\title{
Rubén Vargas Ugarte y la poesía a Santa Rosa
}

\author{
Carlos Arrizabalaga \\ Universidad de Piura
}

El historiador jesuita Rubén Vargas Ugarte (1887-1975) quiso escribir una vida de Santa Rosa que no fuese tanto una biografía erudita y prolija, sino unos breves rasgos que formasen "una exacta pintura", según declarara él mismo al "amigo lector", y su mayor intento habría sido diseñar la fisonomía espiritual de la santa. ${ }^{1}$ También escribió las vidas de san Martín de Porres, de santo Toribio de Mogrovejo y de otras figuras destacadas, pero sin duda ninguna de ellas con tal delicadeza como con la que refiere poco a poco los trazos de la vida y memoria de Rosa de Santa María. Quería que prestáramos atención solamente a los epígrafes que forman parte de los paratextos de su libro: el padre Vargas encabeza cada apartado con una selección de versos que diversos poetas han dedicado a la santa limeña, además de citar en el texto más "in extenso" algunos poemas que Vargas Ugarte desea destacar, en concreto los del poeta catalán Jacinto Verdaguer, un poeta admirado especialmente en el mundo católico de aquellas décadas.

Los fugaces y amenos apartados del libro tienen también títulos de carácter lírico o poético: "Floreció el rosal", "Me llamarán bienaventurada", "Heridas de amor", "Se deshojó la rosa", "Lluvia de rosas" (parecen nombres de canciones románticas), aunque algunos de los últimos son ya menos coloridos: "La canonización", "La extensión de su culto". Son 32 acápites y en cada uno encontramos un epígrafe poético, de muy diversas épocas y autores. La poesía hablaba en consonancia con la finura de la rosa y con la devoción de la santa y Vargas Ugarte demuestra una gran sensibilidad hacia la figura de esta mujer santa, además de una gran intuición literaria.

Muchos poetas han escrito composiciones referidas a la vida y la figura de Isabel Flores de Oliva. En el pórtico de su obra, el padre Vargas escogió unos

\footnotetext{
1 Rubén Vargas Ugarte, La flor de Lima. Santa Rosa. Lima, Ediciones Paulinas, 2011. Las primeras ediciones, con el título: Vida de Santa Rosa de Santa María, se publicaron en Lima, Imprenta Villanueva, en 1945 y 1951. Hay una tercera edición con el título: Vida de Santa Rosa de Lima, en Buenos Aires, Imprenta Torres, 1961. Desde 1983 se han hecho tres ediciones, con un nuevo título, siembre bajo el sello de Ediciones Paulinas, la última de las cuales es la que hemos referido, que se ha reimpreso para celebrar este año conmemorativo.
} 
endecasílabos pareados conceptistas del trinitario valenciano fray Juan Bautista Aguilar. Este elocuente religioso los publicó con el nombre de "Canción a Santa Rosa", y probablemente tuvo música y formó parte de celebraciones religiosas. Salió impresa en Varias hermosas flores del Parnaso (Valencia, 1680), donde él mismo recoge poesías castellanas de autores famosos, además de unas cuarenta composiciones de su propia pluma. El padre Vargas posiblemente los había encontrado en una curiosa antología reparada por Juan Pérez de Guzmán (18411928), publicada en Madrid en 1891, con todas las poesías castellanas que tenían como tema la reina de las flores. ${ }^{2}$ El padre Vargas recoge solo una docena de versos:
¡Oh, mil veces feliz!, pues que dichosa
en el mundo, jardín, luciste rosa, y en tu purpúrea flor por su ventura herido breve pie la dio hermosura, y a ti en rara virtud, con gran fineza, larga mano de Dios te da belleza.
Vive entre espinas, reina de las flores, esa que a hermoso prado ofrece honores, y entre penas que glorias tú imaginas, reina resides, siendo las espinas, quien te fabrica en ansias transitorias, trono de penas para eternas glorias.

Otro de los poetas citados en los mencionados epígrafes es Clemente Althaus (1835-1881). Hijo de un militar alemán que participó en las luchas de la Independencia y de una dama arequipeña, es uno de los más destacados poetas románticos peruanos, junto con Juan de Arona, Ricardo Palma, Felipe Salaverry y Luis Benjamín Cisneros. Son tiempos de amargas rivalidades políticas, crisis, discordias insalvables y amenazas diversas de dentro del país y desde el extranjero. Vargas Ugarte escoge una parte del poema dedicada a la contemplación y alabanza, una de sus más hermosas octavas. El poeta la invoca con un himno a Santa Rosa poderoso, para que su presencia, modelo de pureza y de virtud, ponga fin a las divisiones y favorezca la unión y la felicidad de los peruanos, y que el nombre de su nación no sea nunca por ello motivo de escarnio. Hay claras alusiones a las circunstancias del momento:

¡Oh del Señor inmaculada esposa!, joh de pureza y de virtud modelo!,

\footnotetext{
2 Juan PÉREZ de GuZMÁn, La rosa; manojo de la poesía castellana formado con las mejores producciones líricas consagradas á la reina de las flores durante los siglos XVI, XVII, XVIII y XIX. Madrid, Imprenta de M. Tello, 1891-1892, pp. 426-427.
} 
tú que la flor más bella y olorosa un día fuiste del nativo suelo, y hoy eres viva trasplantada rosa en los floridos cármenes del cielo; flor que el Eterno con deleite mira y cuyo aroma recreado aspira, orgullo del moderno continente, y de sus pueblos inmortal patrona; tú que circundas a tu blanca frente de luceros espléndida corona; ¡oh, el mayor timbre de la patria gente!, tú de quien este suelo más blasona que del oro y la plata con que un día el universo pobre enriquecía: vuelve los ojos a la triste tierra que tanto amaste en tu primera vida; los males mira que en su seno encierra, los vicios mira que en su seno anida; víctima vela de la cruda guerra y furente discordia fratricida; mira cuán presto en bandos se desune la que extranjero agravio deja impune.

Ese extranjero agravio había sido, por supuesto, el combate del 2 de mayo. Para hablar de las fiestas por la canonización de la santa limeña, Vargas Ugarte recoge los versos de Agustín Moreto y Cabana (Madrid 1618-Toledo 1669), quien dejó inconclusa una Comedia famosa. Santa Rosa del Perú, sobre la vida de la santa en dos jornadas que fueron acabadas con una tercera rematada por don Pedro Francisco Lanini y Sagredo, un autor menos destacado y treinta años más joven que Moreto. La obra empieza con unos músicos que cantan alegremente, y a lo largo del texto abundan las alabanzas y el tono festivo:

Celebrad rosa, que hace

cielos de Lima los prados,

pues su hermosura empobrece

toda la luz de los astros.

La obra celebra beatificación de Isabel Flores de Oliva (1586-1617) y se publicó en 1671, año de la canonización de la primera santa americana. ${ }^{3} \mathrm{Su}$

\footnotetext{
3 El papa Clemente X la proclamó santa el 12 de abril de 1671, acontecimiento que también se celebró con gran alegría. Ver Miguel ZugAsti, "Santa Rosa de Lima, una santa del pueblo con sus fiestas y comedias para el pueblo", en José María Díez Borque (dir.), María Soledad Arredondo Sirodey, A. Martínez Pareira y Gerardo Fernández San Emeterio (eds.), Teatro
}

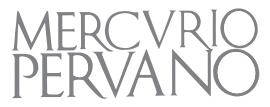


representación formaría parte de los festejos religiosos que se celebran en España y el Perú en honor a la nueva patrona de América y Filipinas, aunque faltan documentos que lo confirmen, pero el hecho de que se le hubiera encargado a alguien la terminación de la obra así lo indica. Se conserva un volumen impreso sin noticia de fecha ni de editor. La otra edición temprana que tuvo la comedia apareció en el volumen: Parte treinta y seis, Comedias escritas por los mejores ingenios de España, en Madrid, por José Fernández de Buendía, 1671. ${ }^{4}$ Moreto ensalza a Rosa de Santa María con referencias llenas de luz y color:
Ser reina de las flores
la rosa es común,
y de las reinas, reina
la Rosa del Perú.
Teniendo a Lima el cielo
envidia de su luz,
trocaron sus estrellas
el nácar al azul.
Engrandézcase el Perú
si la plata le enriquece,
que la Rosa le ennoblece
con belleza y con virtud. ${ }^{5}$

La defensa de la fe católica se contempla en el marco de la expansión de la religión católica en el Nuevo Mundo, que antes de la llegada del Evangelio representa la morada tradicional de la herejía, las tinieblas y la idolatría. Por ello el demonio está deseando que fracase la evangelización y se muestra colérico por el triunfo de la santa. "Ya voy rabiando de verme / por una mujer vencido", declara en un momento dramático.

Los festejos previos, por motivo de la beatificación de Santa Rosa, como se sabe, tuvieron lugar en la basílica de San Pedro de Roma el 15 de abril de 1668. En Madrid se desarrollaron en octubre de ese mismo año. En Lima las celebraciones acontecieron casi un año después, el 30 de abril de 1669, justo cuando Rosa es declarada oficialmente patrona de Lima y el Perú. ${ }^{6}$ De nuevo en

\footnotetext{
español de los Siglos de Oro: dramaturgos, textos, escenarios, fiestas. Madrid, Visor, 2013, pp. 117-151.

4 Ver Miguel ZugastI, “Santa Rosa de Lima, una santa del pueblo..., pp. 117-151.

${ }^{5}$ Se conserva un volumen impreso sin noticia de fecha ni de editor. La otra edición temprana que tuvo la comedia apareció en el volumen Parte treinta y seis, Comedias escritas por los mejores ingenios de España, en Madrid, por José Fernández de Buendía, 1671. Ver ahora la edición de la comedia preparada por Miguel Zugasti, en Agustín MoRETo, Segunda parte de comedias, V. No puede ser. Santa Rosa del Perú. La fuerza del natural. Kassel, Reichenberger, 2016. ${ }^{6}$ Ver María Luisa Loвato, "Villancicos de Calderón de la Barca para la beatificación de Rosa de Santa María (1668)." Golden-Age Essays in Honour of Don W. Cruickshank. Monográfico del Bulletin of Spanish Studies 90 (2013): pp. 735-749. El texto citado está en p. 741.
} 
1771 se celebraron festejos por la canonización de la santa limeña. El dominico Fray Juan Menéndez, regente mayor del insigne colegio de Santo Tomás, estuvo a cargo de la relación de los festejos. La reprodujo el padre Rubén Vargas Ugarte y ahora está disponible en internet, aunque tampoco se ha realizado hasta ahora una edición filológica o un estudio detallado de este otro interesante documento. ${ }^{7}$

Con motivo de aquellas celebraciones católicas se convocaron certámenes poéticos en Madrid y también en Lima y se publicaron relaciones que recogen los poemas que se compusieron para la ocasión. El padre Vargas publicó la relación de fiestas que se hizo en Lima por la beatificación, y en un epígrafe de la biografía de la santa recoge versos posteriores de Juan Menéndez. No se ha hecho todavía una edición filológica de esa ni de otras relaciones de fiestas y sería bueno que este centenario fuera motivo para que estos textos salieran a la luz adecuadamente editados con información de los autores y notas aclaratorias.

Agustín Moreto fue también autor de coplas y villancicos que formaron parte de las celebraciones en torno a la beatificación de Isabel Flores de Oliva. Han sido estudiados también por el profesor Zugasti. En ellos, pone en relación la idea de la santidad con la imagen del jardín, en este caso dominico, referencia a los meses de nacimiento y muerte de la santa y con una clara alusión a la ciudad de Lima, donde todo el año se siente un clima primaveral:

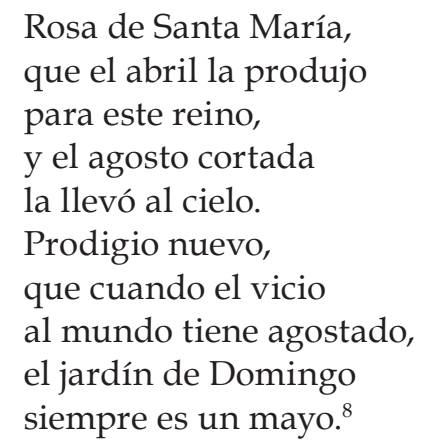

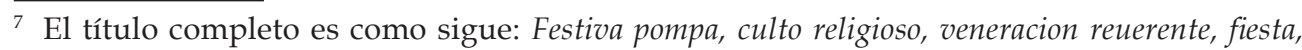
aclamacion, y aplauso. A la feliz beatificacion de la bienauenturada virgen Rosa de S. Maria. Tercera del Orden de Predicadores. Segunda Catalina Senense de la Iglesia. Primera fragrante flor, y fruto opimo [sic] desta plaga meridional. Tesoro escondido en el campo fertil desta muy noble, y muy leal Ciudad de Lima. Descubierto por N.B.P. Clemente Nono. Patrona tutelar vniuersal de su dichosa patria, y dilatados Reynos del Peru. En este Conuento del SS. Rosario de la misma orden. En Lima, Año de 1671. Mujica reproduce buena parte del contenido de esa relación, incluyendo también, entre otras composiciones, las redondillas que lucían el tablado levantado en la Plaza Mayor de Lima: “De la fuente soy memoria, que en Lima con grande audacia / de Rosa aplaudió la gracia / y aquí festeja su gloria". Ver Ramón Mujica Pinilla, Rosa limensis. Mística, política e iconografía en otrno a la patrona de América. Lima, Banco Central de Reserva del Perú, Instituto Francés de Estudios Andinos y Fondo de Cultura Económica, 2001, p. 301. 8 Ver Miguel Zugasti "Cuatro villancicos de Agustín Moreto a la beatificación de Rosa de Lima", en E-Humanista. Journal of Iberian Studies. Santa Barbara (California), 23, 2013: http://

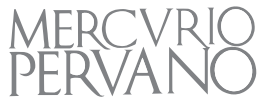


Hubo en ese momento muchas otras expresiones de fervor religioso en torno a la santa limeña. La profesora María Luisa Lobato ha estudiado con prolijidad el conjunto de poesías en honor a Santa Rosa que se publicaron bajo el título: Rasgo breve, disceño [sic] corto del religioso culto que la Nobleza Peruana consagró en el Real Convento de Santo Domingo de esta Corte a la bienaventurada Rosa de Santa María, natural de la ciudad de Lima, en obsequio de su solemne Beatificación. El autor fue Nicolás Matías del Campo y de la Rinaga, caballero de la Orden de Santiago, y estaba dedicado al presidente del Real y Supremo Consejo de las Indias, don Gaspar de Bracamonte y Guzmán, conde de Peñaranda, el año 1668 , como recuerdo de la fiesta patrocinada por tres nobles peruanos, entre los que se contaba Juan Bravo de la Maza, nieto del contador Gonzalo de la Maza, en cuya casa feliz murió la santa. El volumen contiene sonetos, una relación y villancicos compuestos por Calderón de la Barca, Vélez de Guevara, y otros, y entre ellos se encontraban los ya mencionados de Moreto. También hay seguidillas y quintillas de autores diversos. Entre los versos de Calderón dedicados a santa Rosa, podemos recoger los siguientes, que establecen una duda respecto de la razón por la que le pusieron Rosa aunque la flor del lirio era considerada entonces el símbolo de la pureza. ${ }^{9}$

La tradición de los certámenes ha pasado al olvido, pero estaba todavía plenamente vigente a fines del siglo XIX. El padre Vargas recoge un poema del ecuatoriano Leónidas Pallares Arteta, que recibió una mención honrosa en el certamen que organizó la ciudad de Lima con motivo del centenario del nacimiento de Santa Rosa en 1886. Vargas Ugarte escoge los versos más emotivos para el capítulo donde trata la muerte de la Santa, muerte que no hace más que quitarle "la terrenal mortaja / que el vuelo de su espíritu detiene". Otros poetas extranjeros del siglo XIX seleccionados fueron Ruperto Gómez, de Colombia, y Núñez de Arce, de España.

En efecto, los poemas están escogidos en función a la temática de cada capítulo y no siguen un orden cronológico o jerárquico. Los versos de Clemente Althaus los reserva para hablar de la especial relación de Rosa con la naturaleza, y el poema habla del "concierto de alabanzas" que armonizan "los insectos con zumbidos graves". No quiso el padre Vargas dedicar un capítulo señalado a la exaltación nacionalista de santa Rosa, para lo cual Althaus habría sido muy propicio: el padre Vargas pone en consideración una mirada católica, refiriendo las fiestas y la extensión de la devoción a santa Rosa tanto en Lima como en Roma o Madrid y por toda América y Filipinas, atravesando todas las fronteras. Solo al final hace alusión a la "lluvia de rosas", que fueron los muchos milagros que la Iglesia ha reconocido como obra de la intercesión de santa Rosa, quien ha velado por la salvación del Perú en momentos aciagos de invasiones y saqueos,

Www.ehumanista.ucsb.edu/volumes/volume_23/moreto/14\%20ehumanista23.moreto. zugasti.pdf].

${ }^{9}$ Ver María Luisa Lobato, “Villancicos de Calderón de la Barca..., p. 743. 
trayendo paz a las disensiones y conflictos, como "verdadera hermana y abogada nuestra".

Los pasajes de la vida de la santa resuenan con los versos épicos del Conde de la Granja: "A los tres meses de su edad florida" recibió su nombre y no fue trivial que la india mariana entró al servicio de María de Oliva y le puso el nombre: "una rosa del cielo desprendida". Riva Agüero rescató los detalles de la vida y la obra de Luis Antonio de Oviedo y Herrera, pero su apreciación de la obra es bastante negativa, por esos prejuicios anticulteranos de la crítica decimonónica. ${ }^{10}$ Ramón Mugica Pinilla destaca ahora que el conde de la Granja quiso escribir una historia política precolombina y virreinal del Perú "como una pugna cosmológica entre las fuerzas del bien y del mal". ${ }^{11}$ Una rosa pura y perfecta es la estrella que no permite que el mal imponga la idolatría, las guerras civiles y la amenaza de los piratas, así como libra la ciudad de las plagas y temblores. Elio Vélez abunda sobre el asunto indicando que el poema simboliza a santa Rosa como una mujer ejemplar lo que permitirá identificarla desde el criollismo latinoamericano y nacional. ${ }^{12}$ Dirá Enrique Chirinos Soto que sería el nombre de "la persona más ilustre que ha pregonado verdaderamente el nombre de la patria en todos los confines del planeta".13

Todos los epígrafes son versos de distintos poetas hispánicos, salvo dos. Se reserva para los dos últimos los himnos que la liturgia católica ha destinado al oficio de la santa y a su novena: "Ruega por nosotros Rosa / a tu Soberano Esposo."

Todos los epígrafes se componen de entre dos y cinco versos. Solo en un caso recoge un poema completo y no lo hace en el epígrafe sino en el cuerpo del texto. El padre Vargas Ugarte reflexiona sobre el amor de los santos por las plantas y los animales. Rosa amaba la naturaleza porque en todo hallaba motivo para alabar a su Creador y por ello "supo entender muy bien el lenguaje mudo de los seres inferiores que la incitaban a elevarse hasta él". ${ }^{14}$ El poeta catalán Jacinto Verdaguer escribió una poesía, en la que habla de un lirio en vez de albahaca, que es la planta que cultivaba la santa, según sus biógrafos:

\footnotetext{
10 José de la Riva AgÜERo, “Un cantor de Santa Rosa”, en Mercurio Peruano, 1, 1918, pp. 37-53 y 115-122. También “El conde de la Granja”, en Mercurio Peruano, 1, 1918, pp. 225-243.

11 Ramón Mujica Pinilla, Rosa Limensis..., p. 335.

12 Elio Vélez Marquina, Rosa de Indias: discursividad criolla y representación simbólica de la comunidad de Lima en Vida de Santa Rosa de Santa María del Conde de la Granja (1711). Tesis para optar el grado de Licenciado en Lingüística y Literatura. Lima, Pontificia Universidad Católica del Perú, 2009. Un trabajo importante que no hemos podido consultar: Carlos Milla hizo una tesis ofreciendo la edición y anotación crítica del texto, bajo la dirección de Enrique Carrión, pero no se publicó.

13 Enrique Chirinos Soto, Actores en el drama del Perú y del Mundo. Lima, Ediciones de Divulgación Popular, 1961, p. 9.

${ }^{14}$ Rubén Vargas Ugarte, La flor de Lima. Santa Rosa. Lima, Ediciones Paulinas, 2011, pp. 54-55.
}

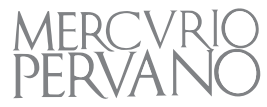


No hay como Rosa de Lima,

si es para amar al buen Dios:

al rezar, un incensario

parece su corazón,

y el alma, una llamarada

que al cielo sube, de amor.

Parece que el propio Rubén Vargas tradujo estos versos al castellano, lo que revela también su buen gusto literario. Otro poeta señalado en los epígrafes es Felipe Sassone, que compuso tres hermosos sonetos a Santa Rosa y un cuarteto le sugiere el título del apartado al padre Vargas: "Mistica Doctora", y aquí trata muy brevemente sobre los escritos de la santa: tema sobre el que la profesora Rosa Carrasco ha publicado este año un hermoso y acucioso libro. ${ }^{15}$

Los poemas escogidos, como hemos señalado, calzan muy bien en la temática de cada apartado. Son justamente famosos los versos de Luis Fernán Cisneros que empiezan describiendo el jardín de santa Rosa, que luego de trescientos años: "lleno de perfumes florece todavía". Es el epígrafe que introduce el tema de la fecundidad de las virtudes de la santa dominica, en especial la fundación de un monasterio que ella había previsto. Merece la pena citar algunos versos:

Hace trescientos años, al caer de la noche, cuando claros luceros desataban el broche y a probar su fortuna descendía el Ensueño con su traje de luna, adormido en un vuelo de blandas mariposas el jardín daba rosas, y así leves sus galas, bajo la suave lumbre y al batir de las alas, humilde entre los muros, perfumado y tranquilo, el jardín era asilo de un rumor de sandalias en piadoso desvelo y de tenues suspiros y de voces del Cielo.

Es un hermoso poema postmodernista, lleno de sugerencias simbólicas e impresionistas. Importa la contemplación y las sensaciones en las que las flores, las mariposas el jardín en el claro de luna, el alma que suspira, las espinas del encierro y la trémula congoja de la espera culminan en una súplica, en el viaje doliente de la hoja caída y desde la única herencia de su amor por la justicia, Cisneros solicita la luz de la mirada de santa Rosa en su ventana de la celeste altura.

\footnotetext{
15 Santa Rosa de Lima: escritos de la santa limeña, Lima, Facultad de Teología Pontificia y Civil de Lima. Provincia Santa Rosa Perú, Editorial San Pablo, 2016.
} 
Cisneros, que ya figuraba como uno de los jóvenes poetas del Parnaso peruano que seleccionó Ventura García Calderón en $1914,{ }^{16}$ a partir de ese poema se convertiría en el poeta de Santa Rosa. ${ }^{17}$ Así lo proclamó Javier Prado en el discurso que daría comienzo a la Academia Peruana de la Lengua: "el laureado cantor de nuestra Rosa de Lima", dijo Prado un año después de que Cisneros ganara, con ese hermoso poema, la Rosa de Oro en el concurso poético convocado por el arzobispo de Lima, monseñor Pedro García Naranjo, en 1917. Aquella jornada fue declarada feriado por la ley 2430 del Congreso de la República. Hubo celebraciones religiosas los días previos y lectura de los poemas ganadores del certamen. La tradición de los certámenes ha pasado al olvido, pero estaba todavía plenamente vigente a fines del siglo XIX e inicios del XX. En 1886 la ciudad de Lima organizó uno por el centenario del nacimiento de Santa Rosa, en que participaron el ecuatoriano Leónidas Pallares Arteta o el colombiano Ruperto Gómez. También participó Germán Leguía y Martínez, justamente el que años más tarde persiguió a los redactores de "la Prensa" y castigaría con el exilio a Luis Fernán Cisneros.

El poeta dejó una grabación de su poema hecha a solicitud de Radio El Sol en 1953, pocos meses antes de su muerte. El poema mismo se publicó ya en una edición especial aquel año 1917 y en un libro que tuvo dos ediciones (por el exilio del poeta), en Buenos Aires, en 1923 y 1924, ampliado en una última edición, corregida y revisada por el autor, en 1933, la misma que lamentablemente no ha tenido otras reediciones. ${ }^{18}$ El poema a Santa Rosa ha aparecido en diversas ocasiones. Se publicó en la Revista Semanal de Federico More (quien lo había tildado de "encumbrado") junto a una plegaria lírica de José Santos Chocano, en agosto de 1931. La revista Mercurio Peruano la incluye en un homenaje al poeta preparado por su hijo Luis Jaime, quien luego se incorporaría a la redacción de la revista, con recuerdos y reseñas de Víctor Andrés Belaunde, Felipe Lovoni y Enrique Chirinos Soto. Fue en el número 328 de 1954, con motivo del fallecimiento de este gran poeta, periodista y diplomático peruano. Cisneros se interesó también por el Conde de la Granja y su poema a Santa Rosa "en las octavas pétreas del siglo", que constituye

\footnotetext{
${ }_{16}$ Ventura GARCía CALDERÓn lo había mencionado con anterioridad en su estudio y antología: Del Romanticismo al Modernismo. París, Paul Ollendorf, 1910. Ver Inmaculada Lergo MarTín, Antologías poéticas peruanas (1853-1967). Búsqueda y consolidación de la literatura nacional. Sevilla, Universidad de Sevilla, 2008, p. 189.

${ }_{17}$ Cisneros fue redactor y cronista de revistas taurinas y de los diarios El Tiempo, El País y La Prensa. Ver Enrique ChiRINos Soto, "Luis Fernán Cisneros, director de La Prensa", Mercurio Peruano, 328, 1954, pp. 390-394. También Nancy SALAS ANDRADE, La crónica periodística peruana. Lima/Piura, Editorial San Marcos/Universidad de Piura, 2009, p. 148.

${ }^{18}$ Luis Fernán Cisneros, Todo, todo es amor: versos. Buenos Aires, Gleizer, 1923. Aparece luego como Todo es amor: versos de Luis Fernán Cisneros. Buenos Aires, Poblet hnos., 1933.El primer número de Mercurio Peruano (1918) incluyó de Luis Fernán Cisneros el poema: "Rumor de alas" (pp. 39-40).
} 
según él un testimonio de prestancia (muy en contra de lo afirmado por Riva Agüero).

El poema es seleccionado por Ricardo González Vigil para su excelente antología: Poesía Peruana, Siglo XX, editada por Petroperú. En internet aparece en muchas páginas, a veces con variantes. Por ello es muy necesario hacer una edición cuidada de la poesía de Cisneros. Cuando la primera versión decía: "una sombra blanca perdida en su sendero", otras versiones señalan: "una sombra blanca que erraba en su sendero". Una versión dice "refulge el sendero" y en otra dice: "resurge el sendero". El primer título que puso Cisneros a su poema: "Era una rosa blanca", no se consigna, y se suele conocer con otros nombres, como "Poema a Santa Rosa" o "Canto a Santa Rosa". En realidad, se han escrito muchísimas poesías a la santa limeña, pero el de Cisneros parece que fuera el poema por antonomasia.

Quiero terminar con unas palabras de Belaunde: "El Canto a Santa Rosa fue la mejor culminación de las fiestas del Centenario. Por encima de su valor ocasional está destinado a perdurar, porque no puede separar la fe ardiente, la vida heroica de la Santa, del ambiente de poesía y de gracia de la ciudad que la vio nacer. Magistralmente Luis Fernán supo reunir esos dos rasgos esenciales de esta época admirable. Idéntica vena, el mismo sentido de la gracia femenina en variedad de tono y ritmo, parecen unir el canto místico a Santa Rosa y las gráciles estrofas". ${ }^{19}$

Ha pasado un siglo y con el centenario de Rosa de Santa María celebramos también el centenario de la Universidad Católica del Perú. Y el padre Vargas, que tanto empeño tuvo también por que la institución de inspiración religiosa tuviera la excelencia debida, nos ayuda a advertir la delicadeza con la que los poetas han hablado y han ensalzado a Santa Rosa de Lima. Debemos destacar a modo de resumen que en su selección demuestra, en primer lugar, el deseo de ser representativo al escoger composiciones de distintas épocas y autores, pero al mismo tiempo se advierte su preferencia por algunos poetas. Además del catalán Verdeguer, se puede señalar que escoge cuatro epígrafes del Conde de la Granja: probablemente por la edición de González de la Rosa, ${ }^{20}$ y tres de Luis Fernán Cisneros y de Felipe Sassone, que eran poetas casi contemporáneos. Pallares también tiene dos menciones, y en los demás casos se seleccionan solo para uno de los epígrafes. Vargas Ugarte también selecciona tres veces versos de san Juan de la Cruz, que no tienen a nuestra santa como motivo, pero que sin duda le gustaban.

Finalmente, en el apartado dedicado a la dirección espiritual con que varios religiosos pudieron ayudarla como guía en los caminos del espíritu, el

\footnotetext{
19 Víctor Andrés Belaunde, “Recuerdo de Luis Fernán Cisneros", en Mercurio Peruano, n. 328, 1954, pp. 353-385 (cito p. 363).

${ }^{20}$ Luis Antonio Oviedo y Herrera, Santa Rosa de Lima, Poema heroico. M. T. González de la Rosa (ed.). Lima, Administración del Perú Católico, 1867.
} 
padre Vargas sitúa cuatro versos heptasílabos en romance, atribuidos con las iniciales R.V. que sin duda fueron obra de su propia pluma:

No me dejaste sola por la áspera senda, por donde fui en tu busca, rastreando tus huellas.

El padre Vargas se manifiesta devoto desde la humildad en su sincero deseo de expresar también poéticamente su admiración por santa Rosa, la flor de Lima. Y manifiesta con ella su aspiración a buscar el camino que le acerque a Dios en esta difícil senda de la vida, tan llena de asperezas. 